\title{
A EDUCAÇÃO AMBIENTAL NO AMBIENTE ESCOLAR COMO AUXILIADORA NA FORMAÇÃO DE EDUCANDOS CIDADÃOS
}

\author{
Julianne Marçal Munhoz ${ }^{1}$, Gisele Lángaro Soares ${ }^{1}$, Ana Claudia Silveira Ribeiro ${ }^{1}$, \\ Ticiana Fagundes da Porciuncula de Vilhena ${ }^{1}$, Valdir Marcos Stefenon ${ }^{2}$ \\ ${ }^{1}$ Especialista em Educação pelo Programa de Pós Graduação lato sensu Educação: Interdisciplinaridade e \\ Transversalidade, Universidade Federal do Pampa, Campus São Gabriel \\ munhozmol@hotmail.com \\ 2 Professor Adjunto, Universidade Federal do Pampa, Campus São Gabriel \\ valdirstefenon@unipampa.edu.br
}

\section{RESUMO}

O artigo discute aspectos percebidos por pesquisadoras da educação numa escola de Ensino Fundamental Municipal a respeito da Qualidade de Vida no Ambiente Escolar e que relevância estes aspectos têm na formação e construção de educandos cidadãos. Para tanto, atividades de sondagem foram primariamente desenvolvidas como questionários e brincadeiras. Posteriormente, enfatizando aspectos das áreas de Ciências Naturais, ações foram abordadas, demonstrando um desconhecimento de assuntos da Educação Ambiental, por parte dos educandos, enfraquecendo a construção de cidadãos críticos e atuantes no meio em que estão inseridos.

Palavras-chave: Qualidade de vida; ambiente escolar; educação ambiental; cidadão.

\section{ABSTRACT}

The article discusses aspects of education perceived by researchers in a school in elementary school about the quality of life in the school environment and relevance of these aspects in the formation and construction of citizen learners. To this end, activities were primarily developed as survey questionnaires and games. Later, emphasizing the areas of Natural Sciences, actions have been addressed, demonstrating a lack of issues of Environmental Education, by the students, weakening the construction of critical and active citizens in the middle where they live.

Keywords: Quality of life: school environment, environmental education, citizen.

\section{INTRODUÇÃO}

O efetivo aprendizado escolar está relacionado a diversos fatores, entre os quais a qualidade de vida dos alunos, tanto dentro como fora da escola. A realidade observada previamente em escolas de Educação Básica do município de São Gabriel revela que o ambiente escolar de algumas instituições deixa a desejar no que se refere às condições consideradas adequadas para uma vivência e convivência saudáveis no que diz respeito desde as condições 
físicas do ambiente até o comportamento, hábitos e atitudes, principalmente, dos alunos. Este fato, por sua vez, aponta a necessidade de uma intervenção objetivando mudanças.

$O$ advento do século XXI trouxe mudanças na sociedade, nas relações humanas, no mercado de trabalho. A escola, entretanto, parece ser a que menos mudou, muitos passam por ela, mas pouco intervém de maneira positiva para o seu aprimoramento. Essas instituições educacionais não podem ficar alheias a essas mudanças, precisam desempenhar o seu papel social. A transformação, não só do sistema educacional, mas da sociedade, tem de passar pela escola. É preciso que um novo sentido de cidadania seja construído (FICAGNA e ORTH, 2010). As mudanças podem começar pela escola, partindo do princípio de que todos passam (ou deveriam passar) por ela, pois as grandes transformações não se originam apenas de grandes feitos, mas de iniciativas do dia-a-dia, simples e persistentes. É essencial que a escola desperte nos alunos a capacidade de compreenderem e atuarem no mundo em que vivem, é preciso dar-lhes informações e formação para que possam atuar como cidadãos, organizando-se e defendendo seus interesses e da coletividade. Precisam, porém, aprender a respeitar regras, leis e normas estabelecidas (FICAGNA e ORTH, 2010).

Ao repensarem seu ambiente escolar e como podem atuar positivamente sobre ele, os alunos estarão também repensando o mundo em que vivem, ao serem inseridos nesse processo passarão a valorizar o seu meio, pois, se sentirão como sujeitos transformadores. Como bem diz Freire "meu papel no mundo não é só o de quem constata o que ocorre, mas também o de quem intervém como sujeito de ocorrências. Não sou apenas objeto da História, mas seu sujeito igualmente" (1996, p. 85). E completa afirmando que é preciso que constatemos a realidade, não somente para nos adaptarmos, mas para mudarmos. Essa constatação não nos levará à impotência, mas ao desejo de transformar (FREIRE, 1996).

Nesta perspectiva, faz-se necessário caracterizar os aspectos relacionados a hábitos, atitudes e comportamentos dos alunos em seu dia-a-dia escolar, de modo a identificar intervenções que possibilitem uma melhora na qualidade de vida dentro das escolas, formando cidadãos conscientes de seus direitos e deveres.

Esta pesquisa foi desenvolvida em uma escola da rede pública de São Gabriel, RS, com alunos do Ensino Fundamental, durante o ano letivo de 2011. Foram aplicados questionários e realizadas atividades lúdicas e observações do comportamento dos educandos, de modo a levantar as opiniões e atitudes dos mesmos a respeito dos aspectos abordados.

O objetivo central do trabalho foi investigar os aspectos sociais e morais envolvidos na qualidade de vida na escola, considerando hábitos, atitudes e comportamentos dos sujeitos envolvidos no espaço escolar.

\section{A EDUCAÇÃO AMBIENTAL NA ESCOLA: COMO FUNCIONA}

Entende-se por Educação Ambiental um processo permanente, no qual os indivíduos e a comunidade tomam consciência do meio ambiente e adquirem os conhecimentos, os valores e as habiliades para tornarem-se aptos para agir individual e coletivamente, resolvendo possiveis problemas ambientais. Ainda, a Educação Ambiental, segundo DIAS (1994), se caracteriza por incorporar as dimensões sociais, políticas, econômicas, culturais, ecológicas e éticas, demonstrando que não basta saber de um problema ambiental e tentar minimízá-lo, tem de entendê-lo em todas as dimensões onde estão inseridos os indivíduos. Isso porque é impossível não perceber a evolução da humanidade baseada em transformações que resultantam das buscas de melhores condições de vida e, quanto mais eficientes se tornam essas condições, maiores 
modificações ocorrem no ambiente. Acontece que por muitos anos essa problemática não era questionada e, ainda, era vista como necessária ao desenvolvimento; até que, em algum momento, começou o questionamento do modelo de vida adotado e que consequências este modelo traria para o ambiente.

Nasce a consiência ambiental, percebe-se, a partir deste isntante que toda a modernidade, tecnologia e avanços científicos ( de inegável importância para a humanidade) trazem riscos ao meio ambiente, se não forem bem geridos. Diante desta crise, mudanças de habitos na sociedade moderna se fazem urgentes. A educação surge, então, como edificadora das transformações socioambientais e das práticas ecológicamente corretas que deverão ser adotadas.

A Lei 9795 de abril de 1999, dispõe sobre educação ambiental e institui a Política Nacional de Educação Ambiental dizendo que "todos têm direito à educação ambiental" e que entre outros òrgãos cabe às "instituições de ensino" a incunbêmcia de trabalhar-lhe. Assim, a Educação Ambiental precisa ser trabalhada nas escolas e encarada como viabilizdora de profundas mudanças nas atitudes dos educandos para as soluções dos problemas ambientais. Para tanto, a Educação Ambiental deveria se constituir como uma prática permanente e interdidsciplinar, minimizadora dos problemas ambientais e integradora das práticas sociais (DIAS, 2003).

Assim, a Educação Ambiental tem relevante significado, pois ela prima por gerar consciência, sensibilização, por ampliar a percepção do avanço tecnológico, inserindo o educando como agente deste avanço o que acarreta consequências para o ambiente, mas, ela prima principalmente para a ação, para a prática correta de resoluções de possíveis problemas ambientais, desenvolvendo uma postura, um hábito que diretamente influencia a qualidade de vida do indivíduo, contribuindo para que, segundo Morin (2001) a "cegueira do conhecimento" seja minimizada.

Nas escolas, no entanto, a Educação Ambiental se institucionalizou de forma fragmentada, quando se trabalha é por iniciativa de professores da área de Ciências Naturais, e muito raramente é desenvolvida fora das datas comemorativas do Dia Internacional do Meio Ambiente. Isto ocorre porque a estrutura escolar está articulada em paradgimas que entram em conflito com a teoria e a prática da Educação Ambiental; corroborando para que ela se fortaleça como uma prática isolada por docentes, também isolados, perdida em ações que não se tornam projetos e nem práticas coletivas e contínuas.

Para tanto, a Educação Ambiental na escola tem de tomar uma outra dimensão, pois como aborda os Parâmetros Curriculares Nacionais para o Meio Ambiente:

A problemática ambientel exige mudanças de comportamento, de discussão e construção de formas de pensar e agir na relação com a natureza. Isso torna fundamental uma refelxão mais abrangente sobre o processo de aprendizagem daquilo que se sabe ser importante, mas que não se consegue compreender suficientemente só com a lógica intelectual (PCN Meio Ambiente, 2000, p.180) .

Assim, para formação de educandos cidadãos aquele que segundo os objetivos gerais dos Parâmetros Curriculares Nacionais ( $P C N^{\prime}$ 's) para o ensino fundamental é aquele que é capaz de compreender a cidadania como participação social e política, como o exercício de direitos e deveres políticos, civis e sociais, que adota, no dia-a-dia, atitudes de solidariedade, cooperação e repúdio às injustiças, respeitando o outro e exigindo para si o mesmo respeito; para a formação deste educando é que a escola deve trabalhar a Educação Ambiental conscientizando seus alunos, usando a teoria de forma clara e direta, ajudando o educando a conhecer-se e reconhecer-se agente transformador de sua realidade e,

Assim, a questão ambiental impõe às sociedades a busca de novas formas de pensar e agir, individual e coletivamente, de novos caminhos e modelos de produção de bens, para 
suprir necessidades humanas, e relações sociais que não perpetuem tantas desigualdade e exclusão social, e, ao mesmo tempo, que garantam a sustentabilidade ecológica. Isso implica um novo universo de valores no qual a educação tem um importante papel a desempenhar (PCN Meio Ambiente, 2000, p.180).

É preciso que o paradigma disciplinar no qual a escola utiliza a Educação Ambiental seja transformado, é preciso que educadores, educandos e a escola construam ideias e ideais que se tornem realidade, é preciso que adotem a Educação Ambiental como uma filosofia, um trabalho diário e continuo que aponte respostas e ações concretas no ambiente escolar, fornecendo subsídios para que o educando se construa um cidadão atuante em seu espaço de vivência.

\section{A REALIDADE DA PESQUISA}

A proposta da pesquisa foi medida em seus aspectos qualitativos e quantitativos em uma escola de Ensino Fundamental Municipal em São Gabriel. Nesta escola, 116 educandos foram entrevistados, desde a Educação Infantil até as Séries Finais da Educação Básica. Nas turmas de 4a à 8a séries foram aplicados questionários com 14 assertivas, sendo que algumas questões eram pessoais, outras deveriam ser marcadas com um " $x$ " $e$, ainda, outras deveriam ser enumeradas em ordem de maior à menor importância. Na pré-escola, nas turmas de 1a à 3a séries, exceto a 2a compreendermos que estes educandos estão no inicio de sua alfabetização foram aplicados questionários na forma oral com plaquinhas cujas respostas eram: tá legal e não tá legal. Também, um jogo que abordava aspectos relacionados com a qualidade de vida foi trabalhado com os educandos da oitava série. A partir deste jogo cartazes foram confeccionados, sendo que estes seriam posteriormente afixados nas paredes da escola para que a comunidade escolar pudesse observar.

Resultado, também, da atividade lúdica, o jogo sobre Qualidade de Vida, é que os educandos das séries finais (uma turma de oitava e outra de quinta) do Ensino Fundamental trabalharam o assunto "Lixo". O tema "lixo" foi desenvolvido de forma teórica para a turma de oitava série, eles tiveram uma apresentação de slides que procurava orientar o que era resíduo sólido (lixo), qual a principal composição deste resíduo (plástico, papel, vidro, matéria orgânica, etc.), os graves problemas sociais envolvidos com a forma de como esses materiais eram devolvidos ao ambiente, bem como a melhor maneira de reduzi-lo, reutiliza-lo, recicla-lo e descarta-lo. Posteriormente, como forma prática, os educandos trouxeram lixo de casa e, convidaram alunos da quinta série para fazer o correto descarte na lixeira da escola, esta proporcionava ao aluno a separação do plástico, papel, vidro e metal, apenas. Toda matéria orgânica, conforme observação das pesquisadoras podia ser depositada numa lixeira que ficava dentro do refeitório, sendo que os alunos não tinham acesso a ela durante o intervalo e, material que não era reciclado não tinha destino, assim, poderia ser colocado em qualquer lixeira. Durante a apresentação teórica alguns educandos mostravam-se indiferentes e outros curiosos, deixando claro que era a primeira vez que eles tinham contato com todo aquele assunto. Não muito diferente da quinta série, que em alguns materiais considerados não recicláveis, como saco de salgadinho, eles interpretaram como plástico reciclável ou isopor como papel; uma porque não tinham o conhecimento e outro porque não tinha lugar apropriado para se fazer o descarte.

Apesar de toda informação disponível nos meios de comunicação e com facílimo acesso (televisão, internet, livros, revistas...), mesmo com as orientações dos PCN's, que orientam, entre outros, que o educando compreenda a natureza como um todo dinâmico, sendo o ser humano parte integrante e agente de transformações do mundo em que vive, sabendo diagnosticar e 
propor soluções para problemas reais, colocando em prática conceitos, procedimentos e atitudes desenvolvidos no aprendizado escolar, percebe-se uma fraqueza quanto à abordagem e construção de conhecimentos que deveriam ser desenvolvidos no espaço escolar que para Didonet (2002) não é somente um território, que guarda alunos, livros, professores, mas é um lugar de aprendizagem, há uma docência neste espaço (...), gera ideias, sentimentos, busca o conhecimento (...).

O tema "Lixo" determinou-se ser abordado porque nas abordagens pré-eliminares, ou seja, nos questionários, alguns educandos responderam que colaboravam com a manutenção da limpeza da escola "não jogando lixo no chão, pátio, salas, banheiros, etc." (figura 1); no entanto, nesta mesma abordagem, uma sugestão de melhoria na qualidade de vida no ambiente escolar era justamente "não jogar lixo no chão". Além disso, era visível a utilização incorreta, principalmente de papeis, jogados em lugares inapropriados dentro e fora da sala de aula. Demonstra-se aqui, uma incongruência de pensamento e atitudes enfraquecendo a construção de educandos cidadãos e, talvez o mais preocupante, demonstrando que eles sabem teoricamente o certo, mas não o praticam, contribuindo pouco ou quase nada para uma qualidade de vida no seu ambiente escolar, assim, "o que ocorre fora da sala de aula influencia o que ocorre dentro dela e faz parte da prática" (PERRENOUD, 2002).

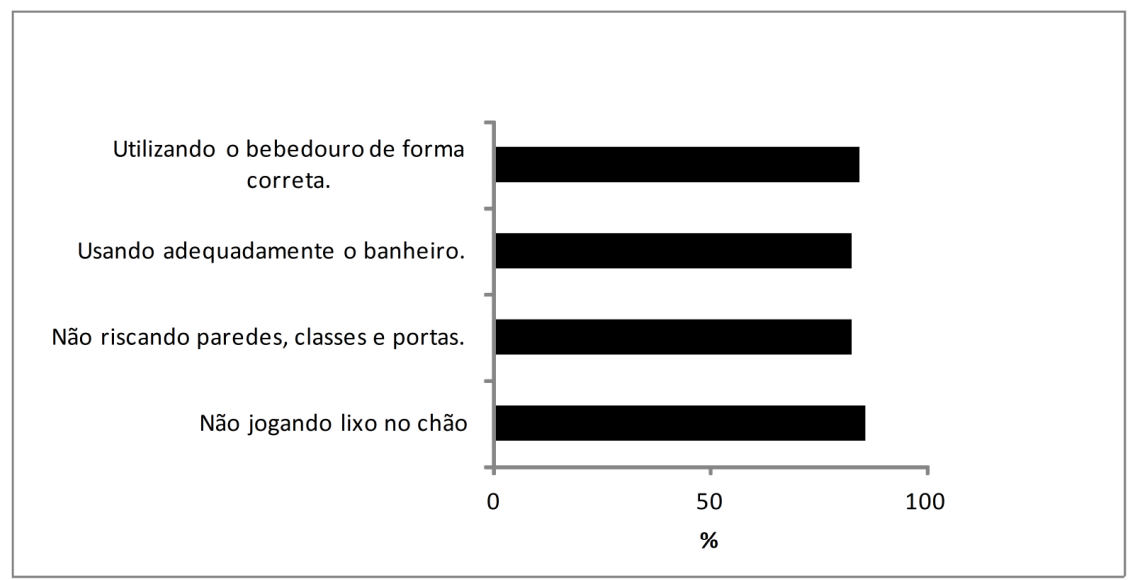

Figura 1. Porcentagem dos alunos de quarta a oitava séries $(n=71)$ que responderam a seguinte questão: você colabora com a manutenção da limpeza de sua escola, de que forma?

Para os alunos da pré-escola, 1a serie e 3 a serie a abordagem com plaquinhas proporcionou observar que as percepções dos pequenos quanto ao descarte do lixo em lugares inadequados é muito mais real que a turma dos maiores, pois quando abordados quanto à limpeza da sua escola, a grande maioria declarou não estar legal (figura 2). 


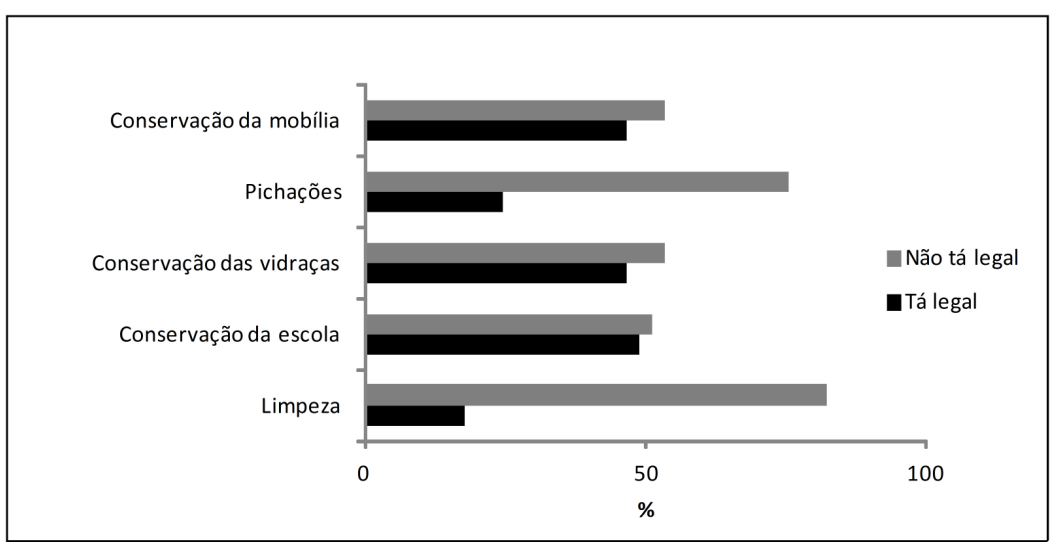

Figura 2. Porcentagem de alunos de pré a terceira serie que consideram que, entre outros aspectos, a limpeza da escola não tá legal $(n=45)$.

Assim, a partir destas observações constata-se que os educandos percebem qual a forma correta de agir na escola, mas não o fazem por não se entenderem como cidadãos. Cabe agora, á escola, contribuir para a construção de indivíduos não apenas no sentido de desenvolver suas habilidades de distinção ou caracterização de determinados assuntos, pois conforme Freire, "formar é muito mais do que treinar o educando no desempenho de destrezas", e sim no sentido de proporcionar ao educando reflexões sobre seu papel, visando seu pleno desenvolvimento crítico e criativo, tornando-o um agente modificador de seu ambiente, um cidadão capaz de melhorar a qualidade de vida em seu ambiente escolar.

\section{CONSIDERAÇÕES FINAIS}

Esta pesquisa, que como já foi mencionado foi desenvolvida numa escola de Ensino Fundamental do Município de São Gabriel e trouxe a emergência de se trabalhar a Educação Ambiental embasada em teorias e práticas orientadas para a construção de educandos críticos, participativos, consciêntes de seu papel na sociedade, ou seja, educandos cidadãos e transformadores fortificando a qualidade de vida em seu ambiente escolar. Apesar de se apresentar fragmentado o conhecimento dos educandos nesta escola, pois se num momento eles dizem que agem de forma a colaborar com um ambiente saudável, sem lixo jogado no chão e num outro momento eles entendem que para esse mesmo local estar adequado deve ter menos papeis esparramados a construção de "alicerces" precisa ser desenvolvido. Para tanto, a Educação Ambiental que se aflorou mais recentemente na nossa sociedade deve permear o cotidiano desses educandos, pois ela tem um nitido papel de descortinar os problemas ambientais, bem como trazer a tona resoluções para tais problemas, fazendo cada indivíduo adotar habitos que colaborem com o meio ambiente, conscientizando-o de seu papel, tornando-o agente modificador, construindo, assim um cidadão que colabora para a qualidade de vida de seu ambiente escolar.

Apesar de não se saber os resultados das intervenções no futuro desses educandos, um aspécto ficou claro nesta pesquisa: há uma necessidade de intervenção objetivando mudanças. É com a Educação Ambiental, norteadora do processo educacional, que o educando tomará 
consciêcia de sua prática, se sentirá agente do processo e, assim, atuará de forma positiva em seu ambiente escolar.

\section{REFERÊNCIAS}

DIAS, Genebaldo Freire. Educação Ambiental: Princípios e Ética. São Paulo: Gaia,1994. DIAS, Genebaldo Freire. Educação Ambiental: Princípios e Práticas. São Paulo:Gaia,2003. DIDONET, Vital, 2002, texto Escola do sonho à realidade, Padrões mínimos de qualidade do ambiente escolar. http://www.tvebrasil.com.br acessado em 23/02/2012

FICAGNA, Marisa; ORTH, Miguel Alfredo. Educação para um novo cidadão: construindo possibilidades ou relações entre a teoria e a prática. In: ANDREOLA, Balduino Antonio et al. (orgs). Formação de educadores: da itinerância das universidades à escola itinerante. ljuí: Ed. Unijuí, 2010. p. 247-259.

FREIRE, Paulo. Pedagogia da autonomia: Saberes necessários à prática educativa. São Paulo: Paz e Terra, 1996

MORIN, Edgar. Os Sete Saberes Necessários à Educação do Futuro, Ed Cortez, 2001.

PERRENOUD, Philippe. A prática reflexiva no Ofício de Professor. Porto Alegre: Artes Médicas Sul, 2002.

PCNs: Ciências Naturais (5a a $\mathbf{8}^{\mathbf{a}}$ séries). Secretaria de Educação Fundamental,Brasília, MEC/SEF, 1998.

PCNs: Ciências Naturais. Secretaria de Educação Fundamental,Brasília, MEC/SEF, 2001. Vol 4.

PCN: Meio Ambiente. Secretaria de Educação Fundamental,Brasília, MEC/SEF, 2000. 